\title{
Prematurity and Language Developmental Outcomes in Preschool Age
}

\section{Tamta Ivanashvili ${ }^{1,2}$}

1 Teaching University Geomedi, Tbilisi, Georgia. Academic Doctor of Medicine, Associate Professor, Pediatrician.

2 Pediatric Clinic Medi22, Tbilisi, Georgia.

Email: Tamta Ivanashvili, tamtaivanashvili77@gmail.com

\section{Abstract}

Global progress in child survival and health cannot be achieved without addressing preterm birth, because every year an estimated 15 million babies are born preterm. Over 1 million children die each year due to complications of preterm birth. Complications highly associated with prematurity include acute respiratory, gastrointestinal, immunologic, central nervous system, as well as longer-term motor, cognitive, behavioral, social-emotional, health, growth and language problems. The aim of the study was assessment of language skills at school aged children born premature and identification of risk factors affecting language development outcomes. Case-control retrospective study was conducted in Child Developmental Center of M. Iashvili Children's Central Hospital (Georgia, Tbilisi).We evaluate language skills in $72 \pm 3$ months old children $(\mathrm{n}=134)$. Children were divided into study $(n=80)$ and control $(n=54)$ groups. Groups were homogenous based on child age, gender, maternal health, maternal education, household income, family structure. Statistical analysis was based on SPSS 20. The difference in language development assessment among the full-term and late preterm children shows low correlation and is not significant (Cramer's V is 0,118; Pearson Chi-square data 0,098 $(\mathrm{p}>0,05)$. While the language assessment data in early and moderate preterm group compared to term infants show significant difference (Cramer's V is 0,354, Pearson Chisquare data 0,004$)$. Statistical analysis show medium correlation, value $(\mathrm{p}<0,05)$, which tell us, that language development is a significantly associated with gestational age. So, small gestational age is correlated with language development problems. Early detection of minimal delays and starting early intervention services can improve developmental outcomes of preterm children. High-quality and stable child care is important for all infants, but especially to those who may be at risk of prematurity.

Keywords: language development outcomes, early and late preterm, preschool age.

\section{Introduction}

The future of human societies depends on children being able to achieve their optimal growth and psychological development. Early childhood development is considered to be the most important phase in life which determines the quality of health, well-being, learning and behavior across the life span [1]. Global progress in child survival and health to 2016 and beyond cannot be achieved without addressing preterm birth, because every year an estimated 15 million babies are born preterm and preterm birth rates are increasing 
in almost all countries with reliable data. Preterm birth is one of the most significant problems in perinatology.Over1million children die each year due to complications of preterm birth [2]. Moreover, striking inequalities exist between developed and developing countries in terms of the survival chances and developmental outcomes of a preterm infant [4]. Many survivors face a lifetime of disability, including learning disabilities and visual and hearing problems. Complications highly associated with prematurity include acute respiratory, gastrointestinal, immunologic, central nervous system, as well as longer-term motor, cognitive, behavioral, social-emotional, health, growth and language problems [3].Disadvantaged children in developing countries who do not reach their developmental potential are less likely to be productive adults $[5,12]$.

One of the main aspects of child development is language and communication skills. Learning to talk is one of the most visible and important achievements of early childhood. A child's speech and language skills allow them to communicate ideas and share and express thoughts and emotions with those around them .Several studies have attributed language impairments in premature infants, especially those born extremely preterm, to a general cognitive deficit affecting several areas of functioning [6]. The study of Foster-Cohen $\underline{\mathrm{S}}^{1}, \underline{\text { Edgin JO}}$, Champion PR, Woodward LJ reveal that associations between gestational age at birth and language outcomes. Specifically, children born extremely preterm $(<28$ weeks' gestation) tended to perform less well than those born very preterm (28-32 weeks' gestation), who in turn performed worse than children born full term (38-41 weeks' gestation). This pattern of findings was evident across a range of outcomes spanning vocabulary size and quality of word use, as well as morphological and syntactic complexity. These findings demonstrate language developmental delay in children born very preterm. They also highlight the importance of gestational age for predicting later language developmental risk in this population of infants [7,12].

According to Rossetti, infants who are born prematurely and have a low birth weight are at risk for many medical complications that could impede later development in areas such as communication. The degree of prematurity significantly impacts children born before 32 weeks, defined as extremely premature, and are six times more likely than their fullterm peers to be receiving special education services by the time they reach school age [8]. Study of Jansson-Verkasalo conclude that at two years of age the toddlers born premature had less complex expressive language skills in addition to producing significantly less words than the full-term group. Some studies have revealed a much higher percentage of persistent language problems in children diagnosed with expressive language delays in the preschool years [ 9 ]. The study of Melissa Woythaler, Marie C. McCormick, at al. shows, that late preterm infants have worse outcomes at school entry, and development is variable during the early school years. The study also reveal that socioeconomic status, gender, language spoken in the home, maternal education and prematurity (even late preterm) have a large impact on language development. 
Most Scientific studies regarding long term outcomes of preterm infants cover early preterm children and show the great impact of early intervention services on developmental outcomes, while the studies regarding the developmental outcomes in late preterm children is quite rare. Assessment of long term outcomes in late preterm children and revealing risk factors has a great importance for working out recommendations for improvement of developmental outcomes in this group of children [12].

Evidence suggests that infants born LPT are at an increased risk of neurodevelopmental delay between 1 and 18 years of life when compared to those born at term. The delay is most evident in the cognitive domain of neurodevelopment. Children born LPT are also at a risk of delayed language development, motor development, and lower academic performance [10]. In recent years, LPIs have increasingly been regarded as "at-risk" rather than "low-risk" infants. They are born developmentally immature and with increased neonatal health concerns compared with term infants. The impact of early neonatal care on longer-term outcomes has not yet been well considered. Study show, that LPIs have more favorable outcomes than very preterm infants but less favorable outcomes than term infants $[11,12]$.

Aim

The aim of the study was assessment of language skills at school aged children born premature and identification of risk factors affecting language development outcomes.

\section{Materials and methods}

Case-control retrospective study was conducted in Child Developmental Center of M.Iashvili Children's Central Hospital (Georgia, Tbilisi). We evaluate language skills in $72 \pm 3$ months old children $(\mathrm{n}=134)$. Children were divided into study $(\mathrm{n}=80)$ and control $(\mathrm{n}=54)$ groups. Control group included 54 healthy, children born term (37 to 42 weeks). Study group -was divided into 2 sub groups: I /consists from 46 late preterm born children (34 \% to $36 \%$ weeks) and II /included 34 early preterm children born at 26-33 weeks of gestation (very (26\% -31\% weeks) + moderate 32\%-33\% weeks) preterm children. Inclusion criteria were child's age $(72 \pm 3$ months), gestational age and weight at birth, child's and family's informed concept. Children with congenital anomalies, genetic disorders, special health care needs, autism-spectrum disorders, cerebral palsy, chronic health problems and children of non-Georgian speaking parents or parents refusing participation in study were excluded from study. Children with single parent also were excluded. Study and Control groups were homogenous based on child age, gender, maternal health, maternal education, household income, and family structure. Information of birth records were collected and parental interview were conducted for every investigated child, that include gestational age, and weight, complications during pregnancy and neonatal period and postnatal history: gathering information from parents, family complains about child's speech and 
language, history of middle ear infections, family history of language difficulties. The parental assessment of child development was conducted based on PEDS (Parents Evaluation of Developmental Status).

We evaluate language skills using 1) Formal and 2) Informal/natural assessment of language development.

1) Formal Assessment was based on specific part (communication part) of The Vineland Adaptive Behavior Scales, Second Edition (Vineland-II)). We asses only one from the four main domains of this test, Communication part, which includes expressive and receptive language skills assessment.

2) Informal/Natural assessment included observation, oral examination, play-based assessment, play behaviors, interest in books, checklists and parent interviews. In most cases we used hearing screening. As a result of evaluation, considering the specific raw scores and children chronological age, we identified special scores of V-scale with the help of basic tables, which shows the range of Vineland test sub-areas data, and is important indicator for weak and strong sides in language development. Magnitude of $\mathrm{V}$ interchanges from low range $\mathrm{V}<9$, till medium (13-17) or high (21 and more) data. Expressive and receptive sub-areas are the important parts of communication sphere, which itself is the main part of assessment of child development. Each individual result for data by general level of language development: High, Medium and elementary levels and basic foundation for rate was magnitude of $\mathrm{V}$-scale scores.

Table 1. The demographic and social characteristics of study cohort:

\begin{tabular}{|c|c|c|c|c|}
\hline Characteristics: & & Control group & I group & II group \\
\hline Gestational age & Weeks & $37-42$ & $34-36$ & $<34$ \\
\hline \multirow[t]{2}{*}{ Gender } & Boy & $29 *-53,7 \%$ & $26^{*}-56,5 \%$ & $18^{*}-52,9 \%$ \\
\hline & Girl & $25^{*}-46,3 \%$ & $20 *-43,5 \%$ & $16^{*}-47,1 \%$ \\
\hline \multirow[t]{2}{*}{ Family income } & Low & $9^{*}-16,7 \%$ & $6^{*}-13,1 \%$ & $4^{*}-11,8 \%$ \\
\hline & Middle & $45^{*}-83,3 \%$ & $40^{*}-86,9 \%$ & $30 *-88,2 \%$ \\
\hline \multirow[t]{2}{*}{ Mother education } & Less than secondary & $5 *-9,2 \%$ & $6^{*}-13,1 \%$ & $4^{*}-11,8 \%$ \\
\hline & Secondary and above & $49^{*}-90,8 \%$ & $40^{*}-86,9 \%$ & $30 *-88,2 \%$ \\
\hline \multirow[t]{2}{*}{ Father education } & Less than secondary & $7^{*}-12,9 \%$ & $8 *-17,4 \%$ & $3^{*}-8,8 \%$ \\
\hline & Secondary and above & $47^{*}-87,1 \%$ & $38 *-82,6 \%$ & $31 *-91,2 \%$ \\
\hline \multirow[t]{2}{*}{ Family size } & 1-4 members & $34^{*}-62.9 \%$ & $37 *-80,4 \%$ & $28 *-82,3 \%$ \\
\hline & 5 and more & $20^{*}-37,1 \%$ & $9 *-19,6 \%$ & $6-{ }^{*} 17,6 \%$ \\
\hline Number of children & $\mathrm{N}=$ & $54^{*}$ & $46^{*}$ & $34^{*}$ \\
\hline
\end{tabular}

Child * 
Result: Overall, of all 134 children - 40,3\% ( $n=54)$ were full term, 34,3\%(n=46) were late preterm, 25,4\% ( $\mathrm{n}=34)$ were early + moderate preterm. The demographic and social characteristics of study cohort are summarized in table1.

Our study revealed that children born preterm have significantly lower language skills. Results show that children with high and medium scores (were $80,4 \%$ in group I (late preterm children), $58,8 \%$ in group II( moderate +early preterm children) while in control group accordingly $88,9 \%$. Children with elementary scores were in group I- 19,6\%, in group II-41, $2 \%$ and in control group $11,1 \%$. So, our study shows that LPIs have more favorable outcomes than very preterm infants but less favorable outcomes than term infants. There seems to be a continuous relationship between decreasing gestational age and increasing risk of adverse outcomes such as language development. The results of language developmental data are presented in Table 2.

Table 2. The results of language assessment:

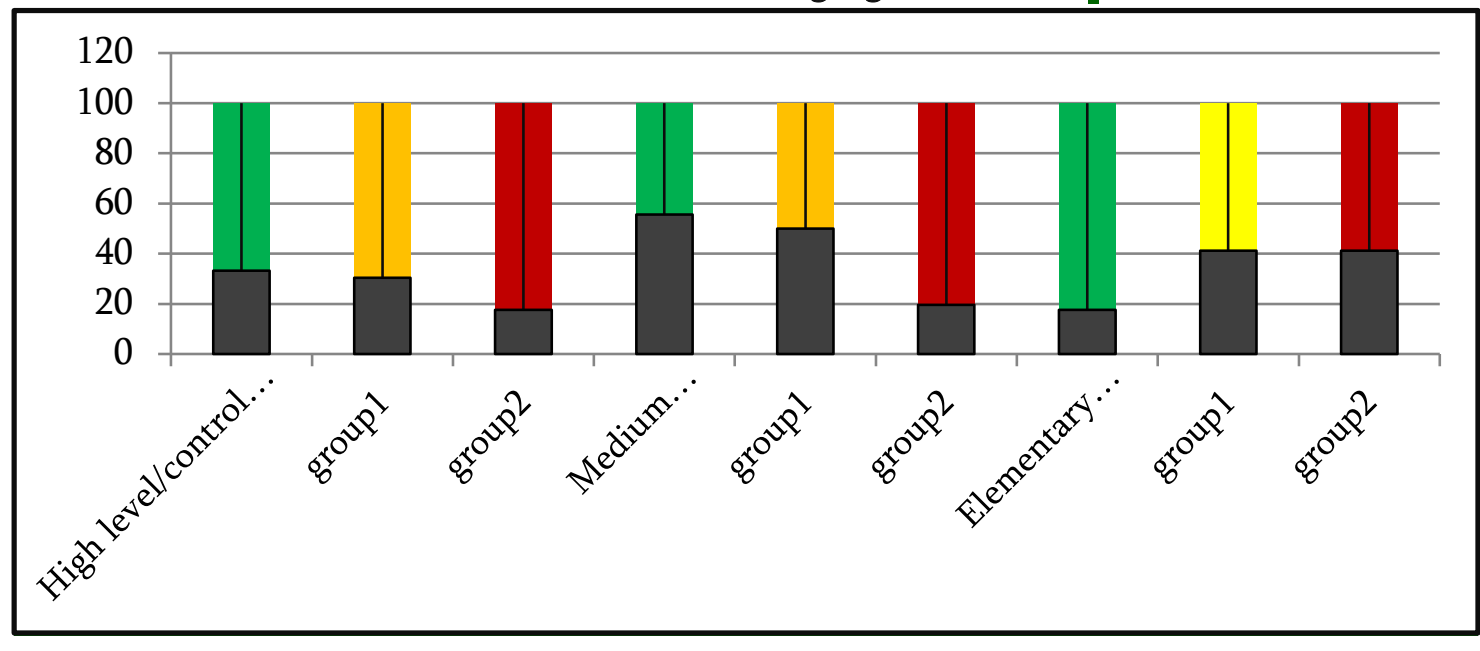

High level Medium level Elementary level

\begin{tabular}{|c|c|c|c|}
\hline Control group & $18^{*}-33,3 \%$ & $30^{*}-55,6 \%$ & $6^{*}-11,1 \%$ \\
\hline I Group $\left(\mathrm{n}=46^{*}\right)$ & $14^{*}-30,4 \%$ & $23^{*}-50 \%$ & $9^{*}-19,6 \%$ \\
\hline II Group $\left(\mathrm{n}=34^{*}\right)$ & $6^{*}-17,6 \%$ & $14^{*}-41,2 \%$ & $14^{*}-41,2 \%$ \\
\hline Child * & & & \\
\hline
\end{tabular}

After assessment we analyzed that $21,64 \%(n=29)$ of children had different kind of important problems. Group I - expressive language problems, receptive language problems. Group II -expressive language problems, receptive language problems. Control group expressive language problems, receptive language problems. At the same time $50 \%$ of all study children $(n=67)$ had medium data, that means they had slight interruption in language skills. Only 28, $36 \%(\mathrm{n}=38)$ had problem-free results. 
We also analyze our data by t-test, the independent-samples test which compares the means between two unrelated groups. We compare language development assessment results and groups with different gestational age and get such results: Sig 0,571; $(p>0,05)$; mean difference 1,446; Std. error difference 1,104; This value is not significant, so gestational age (34-36 weeks) is not associated with child's language development. Effect size $r=0,1$ (small effect) explains $1 \%$ of the total variance; Sig 0,037; ( $<<0,05$; Mean difference 5,038; Std. error difference 1,228; We got a significant value and it means, that child's language development is highly linked with small+ moderate gestational age. Effect size $\quad r=0,3$ (medium effect) - the effect accounts for 9\% of the total variance; ( $\mathrm{r}^{*}$ - effect size: is an objective and standardized measure of the magnitude Of observed effect. Effect size provides an objective measure of tve importance of an effect. Value: from $0=$ to 1 ; effect size $=0$ means, that, there is no effect $)$.

Table 3. Group statistics:

\begin{tabular}{|c|c|c|c|c|}
\hline Groups & $\mathbf{N}$ & Mean & \multicolumn{2}{|c|}{ Std. Deviation Std. Error Mean } \\
\hline Control / Full Term & 54 & 16.19 & 5.129 & .698 \\
\hline Group1/ Late Preterm & 46 & 14.74 & 5.893 & .869 \\
\hline Control/Full Term & 54 & 16.19 & 5.129 & .698 \\
\hline Group2/Early Preterm + Moderate preterm & 34 & 11.15 & 6.301 & 1.081 \\
\hline
\end{tabular}

The difference in language development assessment among the full-term and late preterm children shows low correlation and is not significant (Cramer's V is 0,118 ; Pearson Chi-square data 0,098 ( $p>0,05)$. While the language assessment data in early and moderate preterm group compared to term infants show significant difference (Cramer's $\mathrm{V}$ is 0,354 , Pearson Chi-square data 0,004 . Statistical analysis show medium correlation, value $(\mathrm{p}<0,05)$, which tell us, that language development is a significantly associated with gestational age. So, small gestational age is correlated with language development problems (table 3).

Table 4.

Pearson Chi-square Gramer`s V Correlation

Control group $\rightarrow$ GROUP I $\quad$ Sig.0,498 $(\mathrm{p}>0,05) \quad 0,118 \quad$ Low

\begin{tabular}{llll}
\hline Control group $\rightarrow$ GROUP II & Sig.0,004 $(\mathrm{p}<0.05)$ & 0,354 & Medium \\
\hline
\end{tabular}


Children's language development is influenced by many different factors; In our study we focus on: gender, feeding type, family income, family size and parental education. Male gender is considered as one of the risk-factors for language development. We find that overall girls ( $n=61)$ have better language skills, then boys $(n=73)$. Parents and family members play a crucial role in a child's language development. Parents' education and socio economic status has a great impact on children's global development. We found, that overall children from low-SES families often begin school with significantly less linguistic knowledge $(\mathrm{p}<0.05)$. We did not find significant correlation between family size and school readiness $\operatorname{scores}(\mathrm{p}>0.05)$. In our study about of children $75,37 \%(\mathrm{n}=101)$ had attended preschool. We compare children inside each group, and our data shows, that preschool education significantly improves language development. We also analyzed association between the child language skills and feeding practices. $62 \%(\mathrm{n}=83)$ of study population were breastfeed and 38\% ( $n=51)$ formula feed. We found little relationship between infant feeding practices and the cognitive development, the difference was not significant ( $\mathrm{p}>$ 0.05), that can be explained by small sample size. During our study we reveal, that study participants who watch TV and play an electronic tablet more than 4 hour a day, had worse data, than children with rich, mutually satisfying verbal interactions with parents and pears.

Discussion: Our results showed correlation with prematurity and language development. The results of Allison M. Tanner study indicated that the children born premature consistently performed at a lower level than the children that were born full-term in receptive and expressive vocabulary, expressive language, and phonological short-term memory for non words and digit sequences [1,7,2]. Preterm birth poses risks for the language development of children, especially in the first years of life and they are at substantial risk of language-based learning disabilities that may not be detected until school age, but there are considerable individual differences in outcomes $[4,5]$.

Our results showed correlation with prematurity and language development. The same results were found in several studies: Study of Amanda B. Zerbeto confirms an association between prematurity and language development. In studies that made comparisons between preterm and term infants, there was evidence that preterm infants had poorer performance on indicators of language. It was also observed that children born with lower birth weight had a poorer performance on measures of language when compared to children with higher weight and closer to 37 weeks of gestational age. Regarding the type of language assessed, expression proved to be more impaired than reception. Higher parental education and family income were indicated as protective factors for the development of language. Conversely, lower birth weight and higher degree of prematurity emerged as risk factors. Language difficulties are prevalent in premature children and 
include articulation problems and expressive language delays, which can manifest themselves as poor vocabulary and grammar. Difficulties with phonological awareness are also common and predict later poor reading and writing. In fact, preterm birth is likely to have long-term consequences, affecting linguistic development beyond preschool (7).The results of Allison M. Tanner study indicated that the children born premature consistently performed at a lower level than the children that were born full-term in receptive and expressive vocabulary, expressive language, and phonological short-term memory for non words and digit sequences. [11,12]. Study of Inge L. van Noort-van der Spek et al reveales, that Preterm-born children scored significantly lower compared with term-born children on simple $(P<.001)$ and on complex $(P<.001)$ language function tests, even in the absence of major disabilities and independent of social economic status. For complex language function (but not for simple language function), group differences between preterm- and term-born children increased significantly from 3 to 12 years of age $(P=.03)$. And while growing up, preterm-born children have increasing difficulties with complex language function. The results of Allison M. Tanner study indicated that the children born premature consistently performed at a lower level than the children that were born full-term in receptive and expressive vocabulary, expressive language, and phonological short-term memory for non words and digit sequences [12]. Study of Cusson $\mathrm{RM}^{1}$ shows Language development is delayed in preterm infants. Maternal sensitivity is positively associated with enhanced infant language [11]. Study of NZ Rabie; TM Bird; EF Magann; RW Hall; SS McKelvey shows,that Rates for all outcome variables were statistically significant and elevated for LPI, but adjusted hazard ratios (AHRs) were only significant for the risk of developmental speech and/or language delay. So,late preterm and early term deliveries have adverse long-term neurodevelopmental outcomes, and these outcomes should be considered when determining the timing of delivery. In recent years, LPIs have increasingly been regarded as "at-risk" rather than "low-risk" infants. They are born developmentally immature and with increased neonatal health concerns compared with term infants. The impact of early neonatal care on longer-term outcomes has not yet been well considered; comorbidities, neonatal admission, and surrounding factors have not been fully explored. Systematic measurement of early childhood outcomes, such as those already considered for extremely preterm infant groups, is lacking in the late-preterm population. There is a real need for focused long-term follow-up studies to investigate early childhood development after late-preterm birth [12].

Many children in developing countries are exposed to multiple risks for poor development including poverty and poor health and nutrition. The children will subsequently do poorly in school and are likely to transfer poverty to the next generation. We estimate that this loss of human potential is associated with more than a $20 \%$ deficit in adult income and will have implications for national development. (3) The study found little-to-no relationship 
between infant feeding practices and the cognitive development of children with lesseducated mothers. Instead, reading to a child every day and being sensitive to a child's development were significant predictors of math and reading readiness outcomes $[5$, 6].Some studies suggests that a longer duration of breast feeding benefits cognitive development [7]. The meta-analysis of American Pediatric Academy indicated that, after adjustment for appropriate key cofactors, breast-feeding was associated with significantly higher scores for cognitive development than was formula feeding [28]. The study of Hartley and Sutton, have recently reported that especially boys develop gender stereotypes according to which girls are perceived as academically superior with regard to motivation, ability, performance, and self-regulation [9]. Some studies show gender-dependent differences in the development of infants assessed during the first 2 years of life [3,8].Our data shows, that preschool education had positive role in achievement of language development. Reading and writing skills are better in preschool attended children. Studies show that that preschool attendance have an impact on school readiness and school performance. $[3,1,12]$

Conclusion based on results of our study early and moderate preterm children are at increased risk for low level of language development up to 6 years of age, while late preterm infants does not show significant difference from term population. Male gender, absence of preschool education and low family socioeconomic status can be considered as risk factors for language development. Too many children enter school with physical, social, emotional and cognitive limitations that could have been minimized or eliminated through early attention to child and family needs. Addressing the risk factors and inclusion of early and moderate preterm children in early intervention and preschool services will improve their developmental outcomes. Interventions are required before and around school age to facilitate preterm children to perform at their potential. So daily reading, maybe 15 minutes per day, is an important contribution to the child's developmental outcomes. Since 15 minutes per day adds up to more than 90 hours per year, this can be a substantial investment in helping children reach their full potential in language learning. High-quality and stable child care and preschool education services is important for all infants and toddlers, but especially preterm born children. Inclusion of children in preschool improvesglobal development [12]. 


\section{References}

1.WHO-Early Child Development www.who.int/maternal child.../topics/child/ development/ en/

2. Born Too Soon: The Global Action Report on Preterm Birth www.who.int/pmnch/media/news/2012/201204_borntoosoon-report.pdf

3. Behrman RE, Butler AS. The Preterm Birth: Causes, Consequences, and Prevention.

Institute of Medicine (US) Committee on Understanding Premature Birth and Assuring Healthy Outcomes. Washington (DC): National Academies Press (US); 2007. The National Academies Collection: Reports funded by National Institutes of Health.

4. Who - The worldwide incidence of preterm birth: a systematic review of maternal mortality and morbidityStacy Beck a, Daniel Wojdyla b, Lale Say c, Ana Pilar Betran c, Mario Merialdi c , Jennifer Harris Requejo ${ }^{d}$ Craig Rubens ${ }^{e}$, Ramkumar Menon ${ }^{\text {f }}$ Paul FA Van Look $\mathrm{g}$.

5. Developmental potential in the first 5 years for children in developing countries Sally Grantham-McGregor, ${ }^{\mathrm{a}}$ Yin Bun Cheung, ${ }^{\mathrm{b}}$ Santiago Cueto, ${ }^{\mathrm{c}}$ Paul Glewwe, ${ }^{\mathrm{d}}$ Linda Richter, ${ }^{\mathrm{e}}$ Barbara Strupp, ${ }^{\mathrm{f}}$ and the International Child Development Steering Group ${ }^{\ddagger}$ Lancet. 2007 Jan 6; 369(9555): 60-70.

6. Attention problems and language development in preterm low-birth-weight children: Cross-lagged relations from 18 to 36 months. Luisa A Ribeiro, ${ }^{1}$ Henrik D Zachrisson, ${ }^{1}$ Synnve Schjolberg, ${ }^{1}$ Heidi Aase, ${ }^{1}$ Nina Rohrer-Baumgartner, ${ }^{1}$ and Per Magnus² BMC Pediatr. 2011; 11: 59. Published online 2011 Jun 29.

7. Early delayed language development in very preterm infants: Evidence from the MacArthur-Bates CDI*SUSAN FOSTER-COHEN ${ }^{\mathrm{a} 1} \underline{\mathrm{c} 1}$, JAMIE O. EDGIN², PATRICIA R. CHAMPION $^{\mathrm{a} 3}$ and LIANNE J. WOODWARD ${ }^{\mathrm{a} 4 .}$

8. Holm, A., \& Crosbie, S. (2010). Literacy skills of children born premature.

Australian Journal of Learning Difficulties.

9. Jansson-Verkasalo, E., Ruusuvirta, T., Huotilainen, M., Paavo, A., Kushnerenko, E., Suominen, K., ...Hallman, M. (2010). Atypical perceptual narrowing in prematurely born infants is associatedwith compromised language acquisition at 2 years of age. BMC Neuroscience.

10. Long-term neurodevelopmental outcomes of infants born late preterm: a systematic review Authors Tripathi T, Dusing SC Received 2 July 2015 Accepted for publication 7 August 2015 Published 9 November 2015 Volume 2015:5 Pages 91-111.

11. Early Childhood Development of Late-Preterm Infants: A Systematic Review Jennifer E. McGowan, Fiona A. Alderdice, Valerie A. Holmes, Linda Johnston Pediatrics June 2011, VOLUME 127 / ISSUE 6.

12. International Journal of Sciences: Basic and Applied Research (IJSBAR) ISSN 23074531Evaluation of School Readiness Outcomes in Preterm and SGA Infant Ivanashvili T. a *, Tabatadze T. b , Kherkheulidze M. c , Karseladze R. d , Kandelaki E. e. 


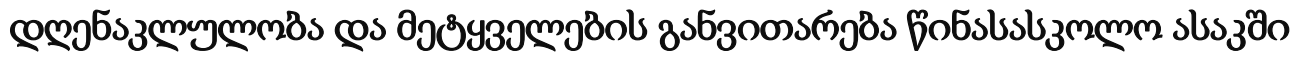

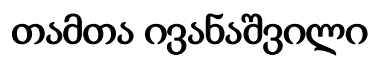

Email: Tamta Ivanashvili, tamtaivanashvili77@gmail.com

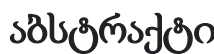

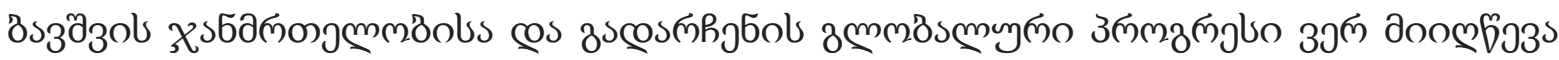

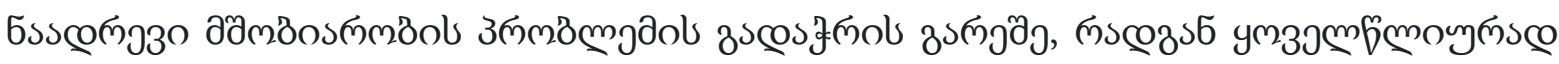

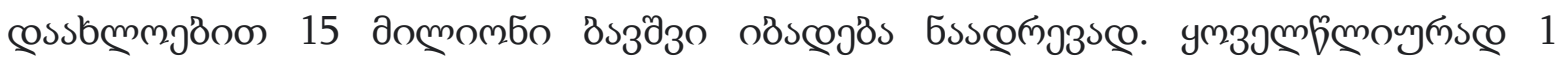

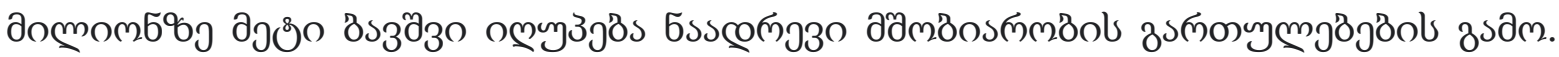

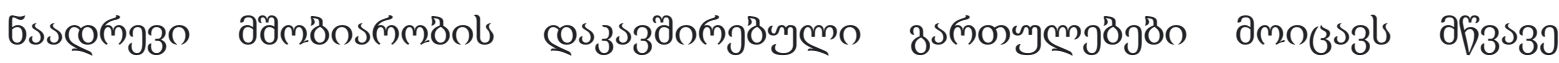

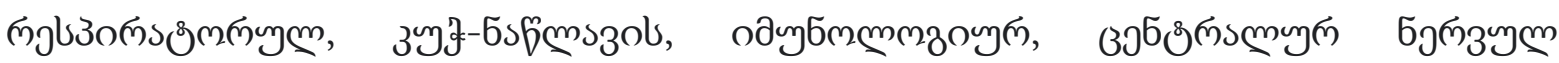

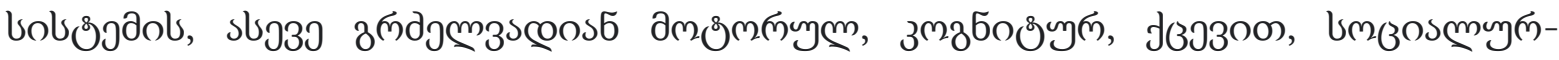

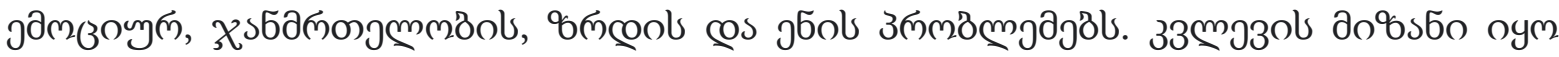

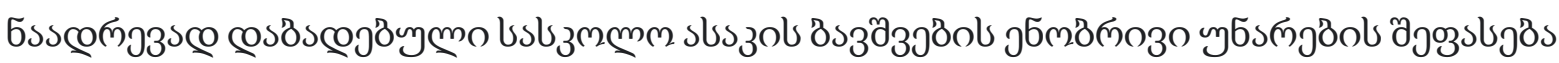

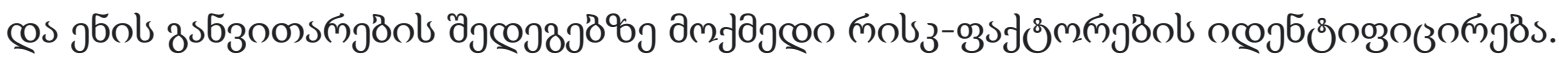

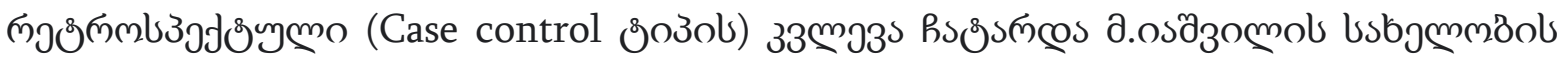

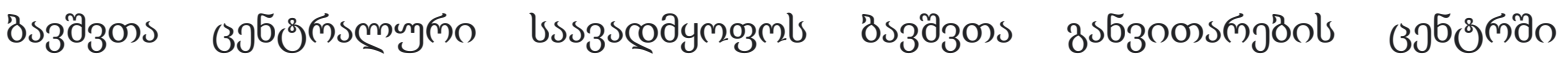

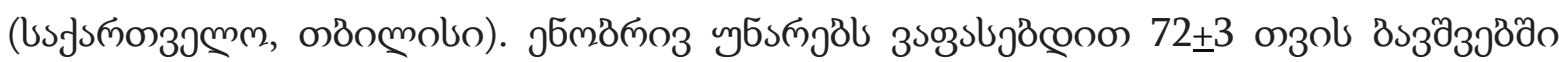

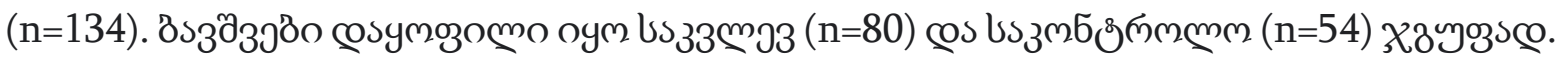

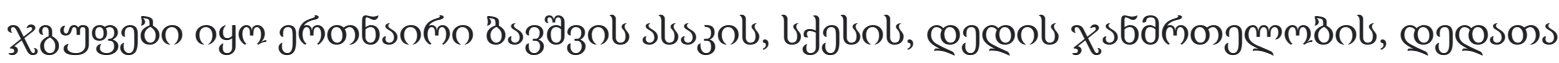

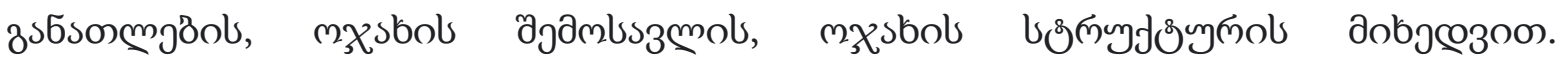

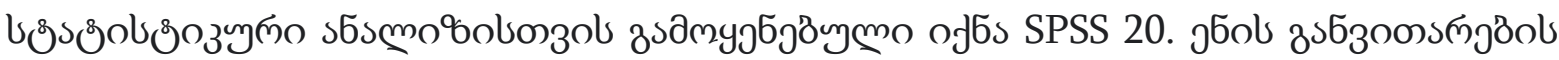

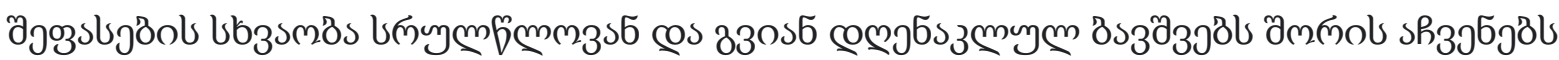

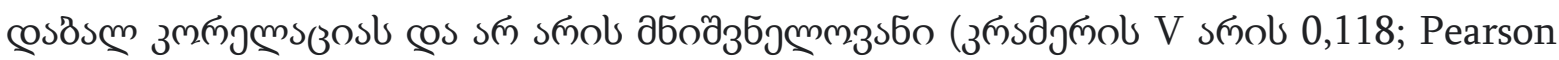

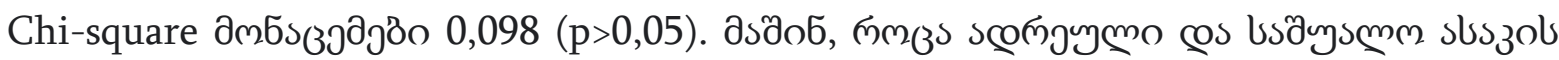

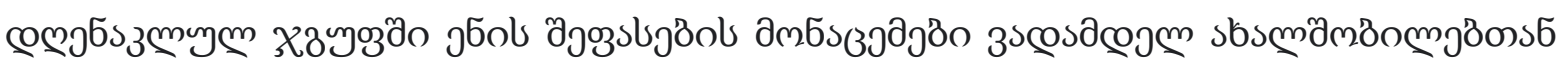

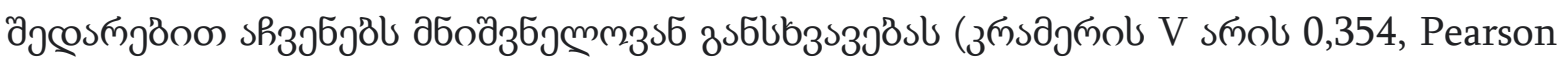

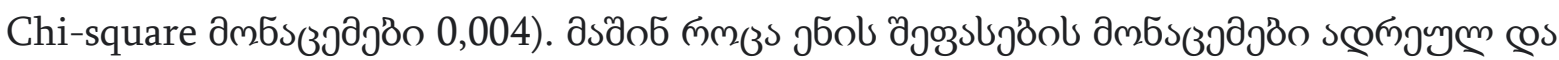

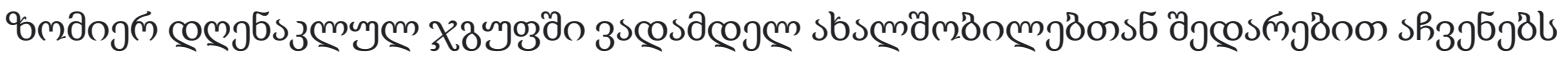

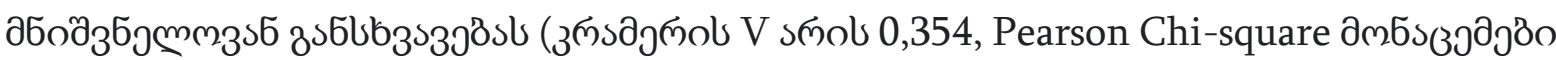

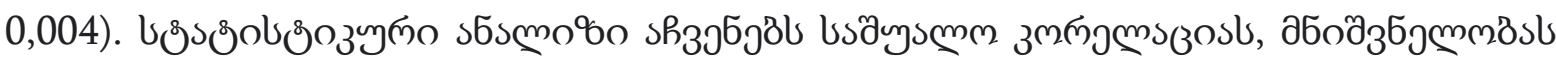

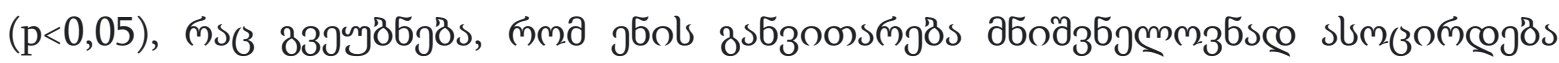

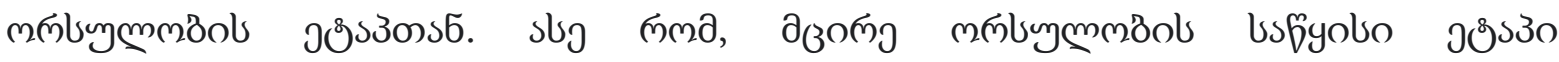

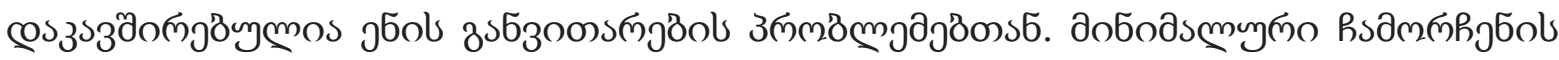

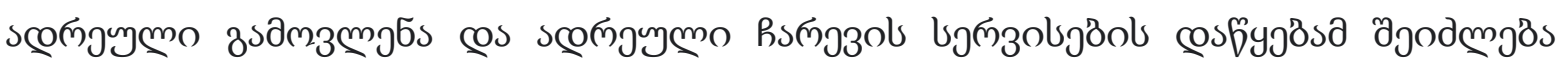

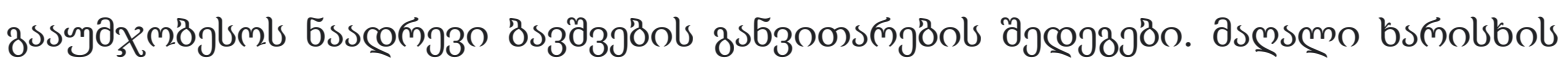

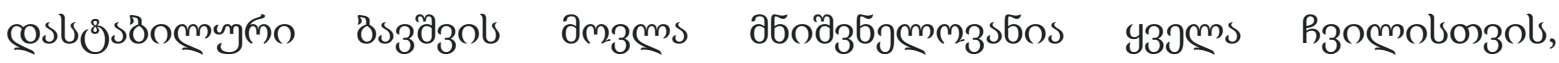

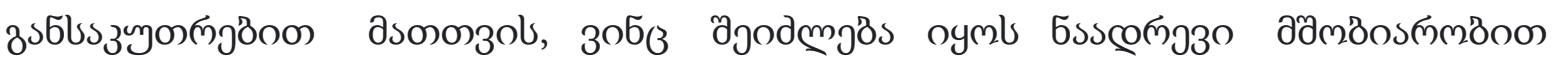




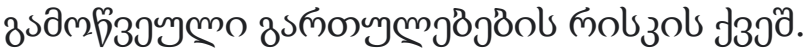

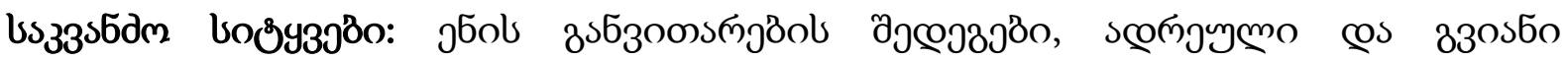

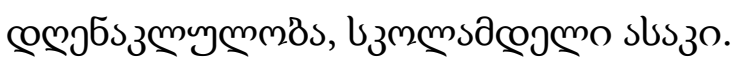

\section{Недоношенность и результаты языкового развития в дошкольном возрасте Иванашвили Тамта}

Email: Tamta Ivanashvili, tamtaivanashvili77@gmail.com

\section{Абстракт}

Глобальный прогресс в области выживания и здоровья детей не может быть достигнут без решения проблемы преждевременных родов, поскольку ежегодно около 15 миллионов детей рождаются преждевременно. Ежегодно более 1 миллиона детей умирают из-за осложнений, связанных с преждевременными родами. Осложнения, в значительной степени связанные с недоношенностью, включают острые респираторные, желудочно-кишечные, иммунологические, заболевания центральной нервной системы, а также долгосрочные двигательные, когнитивные, поведенческие, социально-эмоциональные проблемы, проблемы со здоровьем, ростом и речью. Целью исследования являлась оценка языковых навыков недоношенных детей школьного возраста и выявление факторов риска, влияющих на результаты языкового развития. Ретроспективное исследование «случай-контроль» было проведено в Центре развития детей Центральной детской больницы им. М. Иашвили (Грузия, Тбилиси). Мы оценили языковые навыки у детей в возрасте $72 \pm 3$ месяцев $(\mathrm{n}=134)$. Дети были разделены на основную $(\mathrm{n}=80)$ и контрольную $(\mathrm{n}=54)$ группы. Группы были однородными в зависимости от возраста ребенка, пола, состояния здоровья матери, образования матери, дохода домохозяйства, структуры семьи. Статистический анализ был основан на SPSS 20. Разница в оценке языкового развития среди доношенных и поздно недоношенных детей показывает низкую корреляцию и не является значимой (V Крамера составляет 0,118; данные хи-квадрат Пирсона 0,098 (p> 0,05). Данные языковой оценки в группе недоношенных на раннем и умеренном сроках по сравнению с доношенными детьми показывают значительную разницу (V Крамера составляет 0,354, данные хи-квадрат Пирсона 0,004). Статистический анализ показывает среднюю корреляцию, значение ( $<<0,05)$, которые говорят нам, что Языковое развитие в значительной степени связано с гестационным возрастом. Таким образом, малый гестационный возраст связан с проблемами языкового развития. Раннее обнаружение минимальных задержек и 
начало оказания услуг раннего вмешательства могут улучшить результаты развития недоношенных детей. всем младенцам, но особенно тем, кто подвержен риску недоношенности.

Ключевые слова: результаты языкового развития, ранние и поздние недоношенные, дошкольный возраст. 